\title{
Short-term role of the dietary total antioxidant capacity in two hypocaloric regimes on obese with metabolic syndrome symptoms: the RESMENA randomized controlled trial
}

Patricia Lopez-Legarrea ${ }^{1}$, Rocio de la Iglesia ${ }^{1}$, Itziar Abete ${ }^{2,4}$, Isabel Bondia-Pons ${ }^{1}$, Santiago Navas-Carretero 1,4, Lluis Forga ${ }^{3}$, J Alfredo Martinez ${ }^{1,4^{*}}$ and M Angeles Zulet ${ }^{1,4}$

\begin{abstract}
Background: Dietary strategies seem to be the most prescribed therapy in order to counteract obesity regarding not only calorie restriction, but also bioactive ingredients and the composition of the consumed foods. Dietary total antioxidant capacity (TAC) is gaining importance in order to assess the quality of the diet.

Methods: Ninety-six obese adults presenting metabolic syndrome (MetS) symptoms completed an 8-week intervention trial to evaluate the effects of a novel dietary program with changes in the nutrient distribution and meal frequency and to compare it with a dietary pattern based on the American Heart Association (AHA) guidelines.

Anthropometric and biochemical parameters were assessed at baseline and at the endpoint of the study, in addition to 48-hours food dietary records.

Results: Both diets equally $(p>0.05)$ improved MetS manifestations. Dietary TAC was the component which showed the major influence on body weight $(p=0.034)$, body mass index $(p=0.026)$, waist circumference $(p=0.083)$ and fat mass $(p=0.015)$ reductions. Transaminases (ALT and AST) levels $(p=0.062$ and $p=0.004$, respectively) were associated with lower TAC values.
\end{abstract}

Conclusion: RESMENA diet was as effective as AHA pattern for reducing MetS features. Dietary TAC was the most contributing factor involved in body weight and obesity related markers reduction.

Trial registration: www.clinicaltrials.gov; NCT01087086

Keywords: Antioxidant, Weight loss, Energy restriction, Macronutrient distribution, Dietary components, Nutritional profile

\section{Background}

The World Health Organization (WHO) estimates that at least 300 million people are obese nowadays [1]. Obesity, is strongly associated with comorbidities such as impaired glucose tolerance or diabetes, insulin resistance, dyslipidemia, hypertension, nonalcoholic fatty liver disease, hyperuricemia, and prothrombotic and

\footnotetext{
*Correspondence: jalfmtz@unav.es

'Department of Nutrition, Food Science and Physiology, University of Navarra, Irunlarrea rd 1, Pamplona 31008, Spain

${ }^{4}$ CIBERobn. Carlos III Health Research Institute, Madrid, Spain

Full list of author information is available at the end of the article
}

proinflammatory states, which are related to the onset of metabolic syndrome (MetS) [2-4]. Also according to the WHO estimations, obesity prevalence rates will tend to increase in the next years. So that new effective proposals are needed in order to prevent/counteract the obesity onset and spread.

Dietary strategies are one of the most prescribed therapies to prevent/counteract overweight and obesity [5]. While dietetic programs have traditionally focused on calorie restriction, new nutritional alternatives are nowadays being investigated. They entail macronutrient distribution [6], meal frequency [7], consumption of

\section{() Biomed Central}


bioactive ingredients, such as fiber [8] and n-3 fatty acids [9], glycemic index (GI)/glycemic load (GL) [10] or the dietary total antioxidant capacity (TAC) [11]. Dietary TAC is considered an appropriate approach to measure the cumulative antioxidant properties of food [12], despite its controversial use at evaluating the role of antioxidants in vivo [13]. Oxidative stress is suggested to be involved in the onset of several obesity-related disorders such as hypertension, dyslipidemia, type-2 Diabetes Mellitus and MetS [11]. In this context, dietary TAC is gaining importance as a valuable tool to investigate the relationship between diet and oxidative stressrelated diseases [14]. Furthermore, the influence of the dietary TAC has been poorly investigated in the context of MetS.

Many studies have separately examined the impact of different dietary components, such as macronutrient distribution [15], meal frequency [7], fiber [8], n-3 fatty acids [16], GI/GL [17] or dietary TAC [18]. However, to date, they have not been integrated together on a dietetic plan based on habitual foods intake to combat excessive fat deposition. In this context, the RESMENA-S (MEtabolic Syndrome REduction in NAvarra-Spain) study (www. clinicaltrials.gov; NCT01087086) [19] aimed at evaluating the effect of a novel dietary strategy involving a modified macronutrient distribution, higher meal frequency, increased fiber and n-3 fatty acids consumption, low GI/ GL and high TAC food and at comparing it with the American Heart Association (AHA) guidelines, which is currently considered as a reference dietary pattern to reduce fat mass content and improve MetS markers [20].

\section{Methods}

\section{Study population}

One hundred and five (56 Male and 49 Female) caucasian adults $(49 \pm 10$ years old $)$ presenting obesity determined by a Body Mass Index (BMI) higher than $30 \mathrm{Kg} / \mathrm{m}^{2}$ (mean BMI $=35.85 \pm 4.67 \mathrm{~kg} / \mathrm{m}^{2}$ ) and at least two MetS signs according to the International Diabetes Federation criteria [21] were enrolled in the study and 96 of them completed the trial (Figure 1). The presence of psychiatric disturbances, eating disorders, chronic diseases related with the metabolism of nutrients, major body weight changes in the last three months and difficulties in changing food habits were considered as exclusion criteria. Subjects were recruited through local newspaper advertisements and the Department database. All subjects gave written informed consent (www.clinicaltrials.gov;

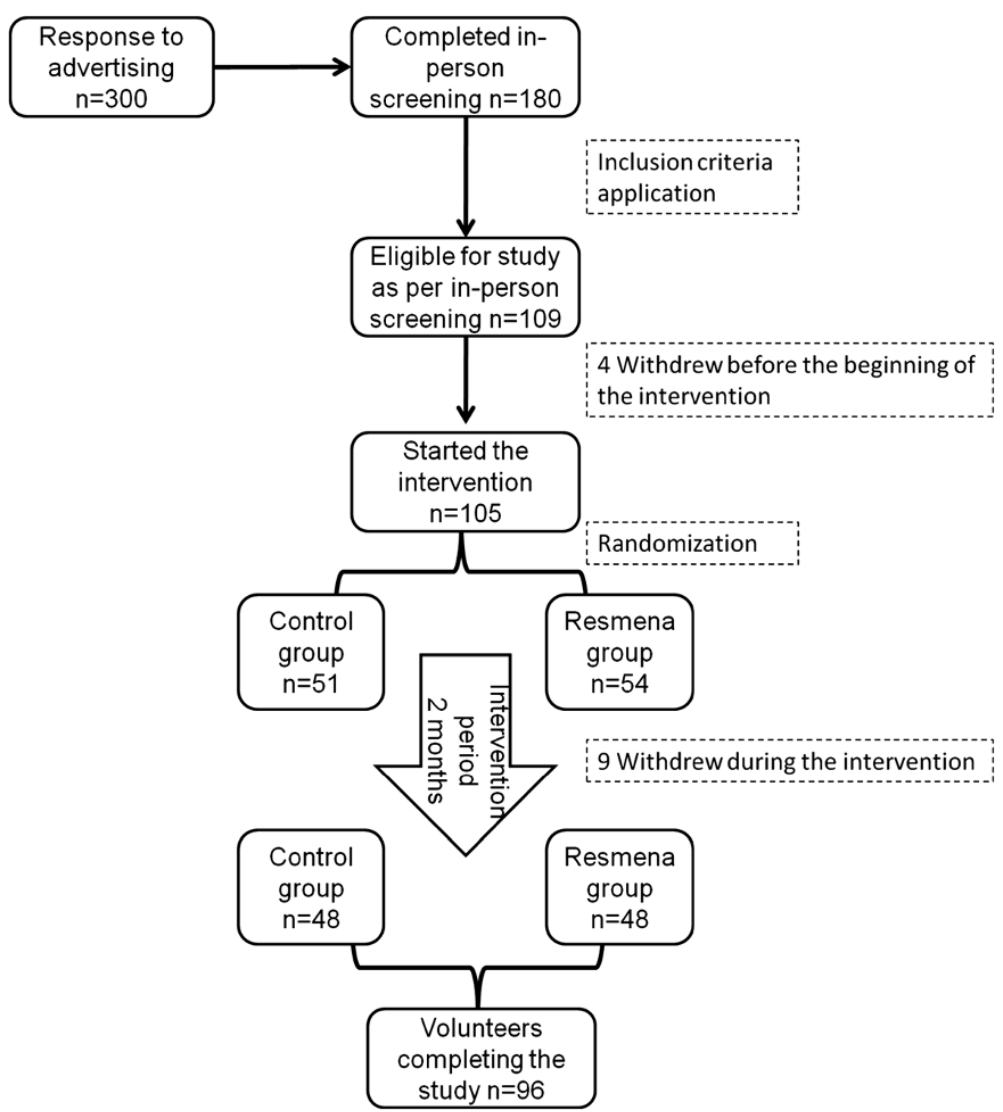

Figure 1 Flowchart of the study subjects from advertisement through to the end of the 8-week intervention. 
NCT01087086) as approved by the Ethics Committee of the University of Navarra (065/2009) and in accordance with the Declaration of Helsinki. There were 9 dropouts along the study period. Baseline characteristics are presented in Table 1.

\section{Study protocol}

A randomized, controlled trial was designed to compare the effect of two dietary strategies for weight loss with different macronutrient distribution on anthropometric measurements and biochemical markers in obese subjects with MetS manifestations. Participants were randomly assigned to the control or the experimental diet (Figure 1). The study was of six months duration in two sequential periods: one intervention period of 8 weeks in which subjects received nutritional assessment every 15 days followed by a self-control period of 4 months in which subjects followed the first period learned-habits. This work reports on the 8-weeks findings.

At each visit, anthropometric assessments and body composition by bioimpedance were measured. Fasting blood and 24-h urine samples were collected and body composition by Dual-energy X-ray Absorptiometry (DXA) was measured at baseline and at the endpoint of the intervention period.

\section{Diets}

Two energy-restricted diets were prescribed and compared. An energy restriction of $30 \%$ was applied to the total energy requirements of each patient. Resting metabolic rate was calculated using the Harris-Benedict equation where the Wilkens adjusted weight was applied. Then, physical activity factor was considered in order to calculate total energy requirements according to the "Food and Nutrition Board, National Research Council: Recommended Dietary Allowances: 10th ed." [22]. The Control diet was based on the AHA guidelines [20], including 3-5 meals/day, a macronutrient distribution of $50-55 \%$ total caloric value from carbohydrates, $15 \%$ from proteins and $30 \%$ from lipids, a healthy fatty acids profile, an intake of fiber of 20-25 g/day and a cholesterol recommendation of $<300 \mathrm{mg} /$ day (Table 2). The RESMENA diet was composed of 7 meals/day including breakfast, lunch, dinner, two snacks in the morning and other two in the afternoon. The macronutrient distribution was as following: $40 \%$ total caloric value from carbohydrates, 30\% from proteins and 30\% from lipids. This pattern also maintained a healthy fatty acids profile, an input of fiber of 20-25 g/day and a cholesterol content of $<300 \mathrm{mg} /$ day. It included an increased input of n-3 fatty acids, an increased amount of natural antioxidants and focused on low GI/GL carbohydrates (Table 2).

Participants were provided a 7-day menu plan in the RESMENA group and a food exchange system plan in the Control group, as previously described [2]. Usual diet was assessed with a semiquantitative 136-item food frequency questionnaire previously validated in Spain for energy and nutrient intake [14]. A 48-hour weighed food record was required at the beginning and at the end of the study. Diet composition was analyzed using the DIAL software (Alce Ingenieria, Madrid, Spain). The sum of eicosapentaenoic fatty acid and docosahexaenoic fatty acid (EPA + DHA) obtained by the DIAL program was used to estimate $n-3$ fatty acids consumption. The Healthy Eating Index (HEI) was calculated using also the DIAL software as described elsewhere [23]. The program gives different values between 0 and 100 considering the servings per day of cereals, vegetables, fruits, dairy products and meat. It also takes into account the percentage of energy provided by total and saturated fats, the amount of cholesterol and sodium per day and the variety of the diet. The final score was classified in five categories: $>80$ points indicates "excellent diet"; 71-80 points = "very good diet"; 61-70 points = "good diet"; 51-60= "acceptable diet" and 0-50 points = "inadequate diet". Protein Quality (PQ) was defined as the ratio of essential amino acid to total dietary protein [24]. Dietary TAC was calculated using the list

Table 1 Selected anthropometric characteristics of the whole sample and categorized by gender at baseline

\begin{tabular}{lcccc}
\hline Variable & Total $(\mathbf{n}=\mathbf{9 6})$ & Male & Female & p \\
\hline Sex & - & 51 & 45 & - \\
Age (years) & $49 \pm 10$ & $48 \pm 9$ & $50 \pm 10$ & 0.194 \\
Weight $(\mathrm{kg})$ & $99.73 \pm 17.85$ & $108.28 \pm 15.94$ & $90.03 \pm 14.76$ & $<0.001$ \\
Height $(\mathrm{m})$ & $1.67 \pm 0.11$ & $1.74 \pm 0.08$ & $1.58 \pm 0.07$ & $<0.001$ \\
BMl $\left(\mathrm{kg} / \mathrm{m}^{2}\right)$ & $35.84 \pm 4.67$ & $35.75 \pm 4.38$ & $35.96 \pm 5.02$ & 0.822 \\
Waist circumference $(\mathrm{cm})$ & $111.10 \pm 12.80$ & $116.27 \pm 10.04$ & $105.24 \pm 13.16$ & $<.89 \pm 0.08$
\end{tabular}

BMI, Body Mass Index.

For the sex variable it is reported the frequency of men and females. Mean and standard deviation data are shown concerning the remaining variables. $p$-value: Comparison between men and women baseline characteristics.

$p<0.05$ was set-up as statistically significant. 
Table 2 Comparisons of the habitual intake, the scheduled diets, the final intake and the adherence

\begin{tabular}{|c|c|c|c|c|c|c|c|c|c|}
\hline \multirow[t]{2}{*}{ Variable } & \multicolumn{3}{|c|}{ Control group $(n=48)$} & \multicolumn{6}{|c|}{ RESMENA group $(n=48)$} \\
\hline & $\begin{array}{c}\text { Habitual } \\
\text { intake (day 0) }\end{array}$ & $\begin{array}{c}\text { Scheduled } \\
\text { diet }\end{array}$ & $\begin{array}{c}\text { Final intake } \\
\text { (day 60) }\end{array}$ & $\begin{array}{c}\text { Habitual } \\
\text { intake (day 0) }\end{array}$ & $p^{a}$ & $\begin{array}{c}\text { Scheduled } \\
\text { diet }\end{array}$ & $p^{b}$ & $\begin{array}{c}\text { Final intake } \\
\text { (day 60) }\end{array}$ & $p^{c}$ \\
\hline Energy (kcal/day) & $2103 \pm 451$ & $1412 \pm 177$ & $1352 \pm 284$ & $2277 \pm 566$ & 0.099 & $1395 \pm 188$ & 0.649 & $1337 \pm 289$ & 0.808 \\
\hline $\mathrm{CHO}$ (g/day) & $\begin{array}{c}186.74 \pm 58.90 \\
(35.52 \%)\end{array}$ & $\begin{array}{c}178.58 \pm 20.15 \\
(50.59 \%)\end{array}$ & $\begin{array}{c}132.37 \pm 35.33^{\$ \$ \$ \$} \\
(39.16 \%)\end{array}$ & $\begin{array}{c}201.66 \pm 65.30 \\
(35.43 \%)\end{array}$ & 0.243 & $\begin{array}{c}128.65 \pm 15.97 \\
(36.89 \%)\end{array}$ & $<0.001$ & $\begin{array}{c}114.55 \pm 31.10^{5 \$} \\
(34.26 \%)\end{array}$ & 0.013 \\
\hline Protein (g/day) & $\begin{array}{c}93.58 \pm 21.63 \\
(17.80 \%)\end{array}$ & $\begin{array}{c}57.01 \pm 5.78 \\
(16.14 \%)\end{array}$ & $\begin{array}{c}60.83 \pm 17.16 \\
(18.00 \%)\end{array}$ & $\begin{array}{c}95.01 \pm 20.06 \\
(16.69 \%)\end{array}$ & 0.738 & $\begin{array}{c}99.54 \pm 13.43 \\
(28.54 \%)\end{array}$ & $<0.001$ & $\begin{array}{c}78.20 \pm 17.46^{\$ \$ \$} \\
(23.39 \%)\end{array}$ & $<0.001$ \\
\hline$P Q$ & $0.30 \pm 0.05$ & $0.31 \pm 0.01$ & $0.30 \pm 0.05^{\$}$ & $0.30 \pm 0.05$ & 0.594 & $0.34 \pm 0.01$ & $<0.001$ & $0.28 \pm 0.05^{\$ \$ \$}$ & 0.070 \\
\hline Protein/CHO & $0.54 \pm 0.18$ & $0.32 \pm 0.01$ & $0.48 \pm 0.18^{\$ \$ \$}$ & $0.50 \pm 0.13$ & 0.224 & $0.77 \pm 0.01$ & $<0.001$ & $0.70 \pm 0.15^{\$ \$}$ & $<0.001$ \\
\hline Total fats (g/day) & $\begin{array}{c}97.29 \pm 27.00 \\
(41.64 \%)\end{array}$ & $\begin{array}{c}46.02 \pm 8.69 \\
(29.33 \%)\end{array}$ & $\begin{array}{c}59.09 \pm 15.51^{\$ \$ \$} \\
(39.33 \%)\end{array}$ & $\begin{array}{c}110.26 \pm 31.84 \\
(43.58 \%)\end{array}$ & 0.034 & $\begin{array}{c}46.98 \pm 7.07 \\
(30.31 \%)\end{array}$ & 0.554 & $\begin{array}{c}56.58 \pm 17.28^{\$ \$ \$} \\
(38.08 \%)\end{array}$ & 0.497 \\
\hline SFA (g/day) & $\begin{array}{c}28.89 \pm 10.13 \\
(12.36 \%)\end{array}$ & $\begin{array}{c}14.02 \pm 2.44 \\
(8.94 \%)\end{array}$ & $\begin{array}{c}14.48 \pm 5.47 \\
(9.64 \%)\end{array}$ & $\begin{array}{c}34.85 \pm 13.64 \\
(13.76 \%)\end{array}$ & 0.017 & $\begin{array}{c}12.70 \pm 1.86 \\
(8.19 \%)\end{array}$ & 0.004 & $\begin{array}{c}16.08 \pm 5.80^{\$ \xi} \\
\xi(10.82 \%)\end{array}$ & 0.181 \\
\hline MUFA (g/day) & $\begin{array}{c}47.35 \pm 12.76 \\
(20.26 \%)\end{array}$ & $\begin{array}{c}20.59 \pm 4.51 \\
(13.12 \%)\end{array}$ & $\begin{array}{c}32.25 \pm 9.18^{\$ \$ \$} \\
(21.47 \%)\end{array}$ & $\begin{array}{c}51.90 \pm 15.42 \\
(20.52 \%)\end{array}$ & 0.118 & $\begin{array}{c}18.96 \pm 3.11 \\
(12.23 \%)\end{array}$ & 0.042 & $\begin{array}{c}24.65 \pm 7.80^{\$ \$ \$} \\
(16.59 \%)\end{array}$ & $<0.001$ \\
\hline PUFA (g/day) & $\begin{array}{l}12.58 \pm 3.80 \\
(5.38 \%)\end{array}$ & $\begin{array}{c}7.54 \pm 1.20 \\
(4.81 \%)\end{array}$ & $\begin{array}{l}7.65 \pm 2.87 \\
(5.09 \%)\end{array}$ & $\begin{array}{l}13.92 \pm 3.79 \\
(5.50 \%)\end{array}$ & 0.088 & $\begin{array}{c}10.77 \pm 1.31 \\
(6.95 \%)\end{array}$ & $<0.001$ & $\begin{array}{c}10.91 \pm 5.56 \\
(7.34 \%)\end{array}$ & 0.001 \\
\hline n3-FA & $0.46 \pm 0.54$ & $0.20 \pm 0.05$ & $0.20 \pm 0.44$ & $0.28 \pm 0.43$ & 0.079 & $0.83 \pm 0.30$ & $<0.001$ & $0.37 \pm 0.49^{\$ \$ \$}$ & 0.096 \\
\hline $\begin{array}{l}\text { Cholesterol } \\
\text { (mg/day) }\end{array}$ & $363.43 \pm 142.46$ & $157.94 \pm 18.44$ & $206.68 \pm 140.82^{\$ \$ \$}$ & $424.43 \pm 162.31$ & 0.053 & $275.75 \pm 46.51$ & $<0.001$ & $241.21 \pm 105.00$ & 0.196 \\
\hline Fiber ( $g /$ day) & $20.07 \pm 8.77$ & $27.57 \pm 1.33$ & $18.75 \pm 8.50^{\$ \$ \$}$ & $21.66 \pm 9.69$ & 0.400 & $22.84 \pm 3.48$ & $<0.001$ & $20.61 \pm 9.01$ & 0.316 \\
\hline Glycemic Index (U) & $579.55 \pm 179.16$ & $487.29 \pm 12.21$ & $367.48 \pm 131.06^{\$ \$ \$}$ & $685.13 \pm 226.21$ & 0.013 & $332.01 \pm 38.04$ & $<0.001$ & $326.70 \pm 121.11$ & 0.131 \\
\hline Glycemic Load (U) & $105.21 \pm 43.52$ & $63.77 \pm 5.47$ & $70.24 \pm 35.70$ & $117.32 \pm 43.92$ & 0.178 & $43.37 \pm 5.04$ & $<0.001$ & $52.03 \pm 26.40^{\$}$ & 0.008 \\
\hline TAC (mmol/day) & $7.36 \pm 3.66$ & $10.85 \pm 0.36$ & $8.88 \pm 2.72^{\$ \$ \$}$ & $8.22 \pm 4.41$ & 0.302 & $17.09 \pm 0.62$ & $<0.001$ & $13.90 \pm 5.05^{\$ \$ \$}$ & $<0.001$ \\
\hline HEI (points) & $60.28 \pm 11.92$ & $86.21 \pm 0.99$ & $70.90 \pm 12.75^{\$ \$ \$}$ & $56.05 \pm 11.11$ & 0.075 & $91.39 \pm 1.80$ & $<0.001$ & $74.41 \pm 10.07^{\$ \$ \$}$ & 0.836 \\
\hline $\begin{array}{l}\text { Meal Frequency } \\
\text { (meals/day) }\end{array}$ & $4.65 \pm 0.59$ & $3-5$ & $4.59 \pm 0.67$ & $5.30 \pm 1.25$ & 0.001 & 7 & N.A & $6.51 \pm 1.06$ & $<0.001$ \\
\hline
\end{tabular}

CHO, Carbohydrates; PQ, Protein Quality; SFA, Saturated Fatty Acids; MUFA, Mono Unsaturated Fatty Acids; PUFA, Poly Unsaturated Fatty Acids; $n-3$ FA, $n-3$ Fatty Acids; TAC, Total Antioxidant Capacity; HEI, Healthy Eating Index; NA, Not Applicable.

$p<0.05$ was set-up as statistically significant. $p^{\mathrm{a}}$ Differences between Control and RESMENA groups intake before starting the intervention. $p^{\mathrm{b}}$ Differences between Control and RESMENA scheduled diets. $p^{c}$ Differences between Control and RESMENA groups intake at the end of the intervention. $\$$ Differences between the scheduled diets and the real intake at final day in both Control and Resmena groups. ${ }^{\$} p<0.05 ;{ }^{\$ \$} p<0.01 ;{ }^{\$ \$ \$} p<0.001$.

from Carlsen et al. 2010, which takes into consideration raw or cooked food preparations [25]. They provide a list of the total antioxidant content $(\mathrm{mmol} / 100 \mathrm{~g})$ of more than 3100 foods, beverages, spices, herbs and supplements used worldwide. The TAC value corresponding to the different scheduled/ingested servings per day was calculated. GI and GL were obtained from Foster-Powell et al. [26] (University of Sydney updated website database 2012).

Participants were asked to maintain their normal physical activity during the study, estimated with a 24-h recall at the beginning and the end of the intervention.

\section{Anthropometric and biochemical assessments}

Anthropometric measurements (body weight, height, waist and hip circumferences) were carried out with the subjects in their underwear. Body weight was measured to the nearest $0.1 \mathrm{~kg}$ using a Tanita SC-330, (Tanita corp, Japan). Height was estimated with a stadiometer (Seca 713 model, Postfach, Germany) to the nearest $1 \mathrm{~mm}$. BMI was calculated as the body weight divided by the squared height $\left(\mathrm{kg} / \mathrm{m}^{2}\right)$. Waist and hip circumferences were measured with a commercial measure tap following validated protocols [19]. Total body fat was measured by a bioelectric impedance Tanita SC-330 (Tanita corp, Japan) and by DXA (Lunar Prodigy, software version 6.0, Madison, WI) as described elsewhere [19].

Glucose, total cholesterol, high density lipoproteincholesterol (HDL-c), triglycerides, alanine aminotransferase (ALT) and aspartate aminotransferase (AST) serum concentrations were measured in an autoanalyser Pentra C-200 (HORIBA ABX, Madrid, Spain) with specific kits. Insulin concentrations were determined by an enzymelinked immunosorbent assay kit (Mercodia, Uppsala, Sweden) in a Triturus autoanalyzer (Grifols SA, Barcelona, Spain). Insulin resistance was estimated by the HOMA index $\{$ HOMA-IR $=$ glucose $(\mathrm{mmol} / \mathrm{L}) \times$ insulin $(\mu \mathrm{U} / \mathrm{ml})] /$ 
22,5\} [5]. Low-density lipoprotein-cholesterol (LDL-c) levels were calculated following the Friedewald formula: LDL-c $=$ TC-HDL-c - VLDL [10].

\section{Statistical analyses}

The results are expressed as mean \pm SD. Normality distributions of the measured variables were determined according to the Shapiro-Wilk test. Differences between the beginning and the end of the period were analyzed by a paired $t$-test. Only those completely the study were analysed. The analysis between both diets (RESMENA vs. Control) was performed through an independent measures $t$-test. A linear regression analysis was applied to assess the potential relationships and associations among the different components of the diet and anthropometrical and biochemical parameters variation. Chi-square test was carried out to compare the percentage of participants from Control and RESMENA dietary groups included in the high-TAC group. A two-way ANOVA was performed in order to assess diet and sex interactions. Analyses were carried out using SPSS 15.1 software for Windows (SPSS Inc, Chicago, USA). Values of $\mathrm{p}<0.05$ were considered as statistically significant.

\section{Results}

\section{Food intake assessment}

There were available data about food intake of 90 participants (48 from Control group and 42 from RESMENA group). No differences were found in food energy intake between the experimental groups at the study baseline, except for total fat and saturated fat intake, GI and meal frequency (Table 2).

The RESMENA group reported a significantly higher protein and lower carbohydrate intake and the protein/ carbohydrate ratio was also higher in this group at the end of the study (Table 2). There were no significant differences between groups either for PQ or total fat intake, but significant differences were found regarding fatty acids profile (Table 2). There were no significant differences in cholesterol intake after the intervention. Concurrently, no differences were found in fiber intake, neither in GI or HEI score. GL was significantly lower $(p=0.008)$ and TAC significantly higher $(p<0.001)$ in RESMENA group, with respect to the AHA group. As designed, consuming the RESMENA diet had an average intake (6.5 meals/day) significantly higher than the control one (4.5 meals/day).

The analysis of 48-h food records showed that in both groups the energy intake was in accordance with the prescribed patterns (Table 2). Protein, saturated fatty acid, polyunsaturated fatty acid (PUFA) and n-3 fatty acids intakes, as well as GL and meal frequency of the Control diet were in agreement with the scheduled pattern (Table 2). RESMENA group adjusted to PUFA, cholesterol and fiber intake and also the GI and meal frequency. RESMENA group did not reach completely the expected values of some components although it achieved an improvement comparing to baseline values.

\section{Anthropometric and biochemical parameters}

Energy restriction resulted in a mean body weight loss of $6.73 \pm 0.71 \mathrm{~kg}$ in the Control diet and $7.09 \pm 0.82 \mathrm{~kg}$ in the RESMENA diet, with no statistical differences between groups (Table 3). Consequently, BMI was significantly lowered in both groups. Every anthropometrical parameter was significantly reduced after the slimming treatments, with no differences between both dietary groups (Table 3). Control and RESMENA groups significantly reduced total cholesterol and triglycerides but there was no significant reduction in LDL-c. Only the AHA group had a significant decrease of the HDL-c values $(p=0.001)$. No changes were observed in the atherogenic ratios TC:HDL-c and LDL-c:HDL-c in none of the groups. Both groups significantly improved glucose metabolism (Table 3 ). The Control diet, but not the RESMENA one induced a significant reduction in ALT $(p<0.001$ vs. $p=0.936)$ and AST $(p=0.001$ vs. $p=0.740)$ transaminases levels, obtaining significant differences among groups (Table 3). No differences between groups were found in any of the other biochemical parameters (Table 3).

Dietary TAC was the major influential factor, as body weight $(p=0.034)$, BMI $(p=0.026)$, fat mass $(p=0.015)$ and AST $(p=0.004)$ were significantly improved by this variable (Table 4). Dietary TAC also seemed to have a potential effect in ALT variations $(p=0.062)$. Concerning GI/GL, a trend towards an influence of insulin was found (Table 4). Since dietary TAC seemed to be the most influencing variable among the dietary analyzed elements, we categorized the sample considering the median value in: high- TAC (>10.629 mmol day $\left.{ }^{-1}\right)$ or low- TAC $(<10.629$ $\mathrm{mmol} \mathrm{day}^{-1}$ ) (Figure 2). As expected, the percentage of subjects from the RESMENA group (71\%) included in the high-TAC group was significantly higher $(\mathrm{p}<0.001)$ as compared with the Control group (29\%). Body weight losses were marginally $(p=0.066)$ different when the subjects were categorized by the dietary TAC (Figure 2). Thus, the group with a higher dietary TAC showed a greater body weight reduction $(-7.52 \pm 0.64 \mathrm{~kg})$ when compared with the low-TAC group $(-6.35 \pm 0.86 \mathrm{~kg})$. Waist circumference decreased marginally towards significant differences between the two groups $(p=0.082)$ being greater in the high-TAC one $(-7.77 \pm 2.07 \mathrm{~cm} v s .-6.15 \pm$ $0.31 \mathrm{~cm}$ ). Fat mass was significantly reduced in both TAC groups and differences between them regarding densitometry fat mass kilograms $(p=0.026)$ were found. The lowTAC group significantly reduces ALT $(p=0.001)$ and AST $(p=0.002)$ transaminases levels, being statistically significant 
Table 3 Changes in selected parameters in Control and RESMENA groups after 8 weeks of nutritional intervention

\begin{tabular}{|c|c|c|c|c|c|c|c|}
\hline \multirow[t]{2}{*}{ Variable } & \multicolumn{3}{|c|}{ Control group $(n=48)$} & \multicolumn{3}{|c|}{ Resmena group $(n=48)$} & \multirow[b]{2}{*}{$p^{c}$} \\
\hline & Visit 1 (day 0) & Visit 2 (day 60) & $p^{a}$ & Visit 1 (day 0) & Visit 2 (day 60) & $p^{b}$ & \\
\hline Weight (kg) & $99.45 \pm 19.21$ & $92.72 \pm 18.50$ & $<0.001$ & $100.00 \pm 16.58$ & $92.91 \pm 15.76$ & $<0.001$ & 0.555 \\
\hline $\mathrm{BMI}\left(\mathrm{kg} / \mathrm{m}^{2}\right)$ & $36.15 \pm 4.95$ & $33.70 \pm 4.80$ & $<0.001$ & $35.55 \pm 4.40$ & $33.03 \pm 4.24$ & $<0.001$ & 0.732 \\
\hline Waist circumference $(\mathrm{cm})$ & $110.94 \pm 13.41$ & $104.18 \pm 12.29$ & $<0.001$ & $111.25 \pm 12.30$ & $103.78 \pm 11.66$ & $<0.001$ & 0.432 \\
\hline Waist/hip ratio & $0.96 \pm 0.10$ & $0.94 \pm 0.09$ & $<0.001$ & $0.96 \pm 0.10$ & $0.93 \pm 0.10$ & $<0.001$ & 0.355 \\
\hline Bioimpedance Fat mass (kg) & $38.97 \pm 10.87$ & $33.68 \pm 10.22$ & $<0.001$ & $39.23 \pm 9.50$ & $33.84 \pm 9.09$ & $<0.001$ & 0.886 \\
\hline DXA Fat mass (kg) & $42.13 \pm 10.18$ & $37.50 \pm 10.39$ & $<0.001$ & $42.56 \pm 9.18$ & $37.30 \pm 8.95$ & $<0.001$ & 0.208 \\
\hline $\mathrm{TC}(\mathrm{mg} / \mathrm{dl})$ & $221 \pm 39$ & $204 \pm 39$ & 0.001 & $219 \pm 48$ & $203 \pm 46$ & 0.020 & 0.943 \\
\hline $\mathrm{HDL-c}(\mathrm{mg} / \mathrm{dl})$ & $46 \pm 10$ & $42 \pm 9$ & 0.001 & $43 \pm 10$ & $41 \pm 10$ & 0.050 & 0.158 \\
\hline LDL-c (mg/dl) & $140 \pm 36$ & $133 \pm 35$ & 0.085 & $137 \pm 41$ & $131 \pm 40$ & 0.374 & 0.888 \\
\hline $\mathrm{TC} / \mathrm{HDL}-\mathrm{c}$ ratio & $4.94 \pm 1.02$ & $4.96 \pm 0.94$ & 0.856 & $5.18 \pm 1.24$ & $5.04 \pm 1.24$ & 0.398 & 0.419 \\
\hline LDL-C/HDL-c ratio & $3.09 \pm 0.77$ & $3.22 \pm 0.78$ & 0.178 & $3.20 \pm 0.83$ & $3.23 \pm 0.92$ & 0.803 & 0.623 \\
\hline TG (mg/dl) & $176 \pm 10$ & $145 \pm 70$ & 0.005 & $194 \pm 123$ & $151 \pm 99$ & $<0.001$ & 0.421 \\
\hline Glucose (mg/dl) & $121.02 \pm 33.87$ & $107.98 \pm 13.71$ & 0.006 & $123.81 \pm 37.82$ & $110.22 \pm 26.18$ & 0.016 & 0.939 \\
\hline Insulin (IU/mg) & $15.30 \pm 11.46$ & $9.32 \pm 7.18$ & $<0.001$ & $14.36 \pm 8.30$ & $9.14 \pm 6.13$ & $<0.001$ & 0.557 \\
\hline HOMA index & $4.69 \pm 3.77$ & $2.61 \pm 2.31$ & $<0.001$ & $4.48 \pm 3.01$ & $2.60 \pm 2.00$ & $<0.001$ & 0.686 \\
\hline $\mathrm{ALT}(\mathrm{U} / \mathrm{L})$ & $37.60 \pm 21.04$ & $27.03 \pm 10.70$ & $<0.001$ & $29.13 \pm 11.59$ & $29.28 \pm 14.20$ & 0.936 & 0.001 \\
\hline AST $(U / L)$ & $25.81 \pm 10.84$ & $20.68 \pm 6.18$ & 0.001 & $21.90 \pm 6.01$ & $22.20 \pm 6.14$ & 0.740 & 0.002 \\
\hline
\end{tabular}

BMI, Body Mass Index; DXA, Dual-energy X-ray Absorptiometry; HDL-c, High Density Lipoprotein-cholesterol; LDL-c, Low Density Lipoprotein-cholesterol; TG, Triglycerides; HOMA, Homeostasis Model Assessment; ALT, Alanine aminotransferase; AST, Aspartate aminotranferase. $p<0.05$ was set-up as statistically significant. $p^{a}$ differences between baseline and final values in Control group. $p^{b}$ differences between baseline and final values in RESMENA group. $p^{c}$ differences between changes in Control group as compared with RESMENA group at the end of the intervention.

regarding the high-TAC group $(p=0.044$ and $p=0.004$, respectively) (Figure 2).

As expected, gender variation influenced anthropometrical and biochemical parameters changes (Table 5). Body weight loss was significantly higher in males than in females $(p=0.008)$, as well as fat mass reduction $(p=0.042)$ (Figure 3$)$. Interestingly, men showed a statistically significant decrease of insulin blood levels $(p=0.020)$. Concurrently, ALT values were significantly reduced in men, while we did not found any changes in this marker in females group (Figure 3). Regarding dietary TAC influence, differences concerning gender were found. Women with higher TAC levels, showed a significantly greater reduction of body weight $(p=0.019)$, BMI $(p=0.028)$ and fat mass $(p=0.007)$, while there were not any variable differences between high or low TAC in the male group.

\section{Discussion}

This study compared the effects of a novel dietary strategy with the AHA pattern [20], considered to be effective to counteract obesity. To our knowledge, this is a pioneer intervention study in patients with MetS features evaluating the effects of an energy restricted diet based on food selection, including a modified macronutrient distribution, an increase in meal frequency, as well as the presence of bioactive ingredients, such as fiber and n-3 fatty acids, and controlling the GI/GL, dietary TAC and HEI score [19].

Evaluating the two prescribed dietary strategies as a whole, both were for weight loss and improved anthropometric and biochemical markers, with minor differences between them. Waist circumference was reduced in all the participants. However, when considering the IDF criteria for abdominal obesity $(>90 \mathrm{~cm}$. in men and $>80 \mathrm{~cm}$. in women) 4 people reached lower values after the dietary intervention (1 man and 1 woman from the Control group, 1 man and 1 woman from the RESMENA group).

Specifically, the individual role of each diet component was analyzed in order to assess the dietary components with major influence on these measurements in a MetS sample. In this sense, several works have studied dietary components effects separately in humans, but available results are controversial $[5,7,13]$.

Recent investigations have focused on the role of the macronutrient distribution in weight reduction treatments instead of considering only calorie restriction [27]. In this context, increasing the dietary protein content has been a frequently-used strategy, due to the increased satiety with a reduction of energy intake in subsequent meals and the higher thermogenic effect attributed to them [6,27]. Thus, in the current work it was prescribed a dietary pattern including the $30 \%$ of total caloric value as protein at the expense of carbohydrates (40\% total caloric value). This 
Table 4 Regression analysis, with change in phenotypical measurements as dependent variable and dietary components as the independent

\begin{tabular}{|c|c|c|c|c|c|c|c|c|c|c|c|c|c|c|c|c|}
\hline \multirow[b]{2}{*}{ Variable } & \multicolumn{2}{|c|}{$\begin{array}{c}\text { Meal } \\
\text { Frequency }\end{array}$} & \multicolumn{2}{|c|}{$\begin{array}{l}\text { Protein } \\
\text { Intake }\end{array}$} & \multicolumn{2}{|c|}{$\begin{array}{l}\mathrm{n}-3 \mathrm{FA} \\
\text { intake }\end{array}$} & \multicolumn{2}{|c|}{ TAC } & \multicolumn{2}{|c|}{ GI } & \multicolumn{2}{|c|}{ GL } & \multicolumn{2}{|c|}{ HEI } & \multirow[t]{2}{*}{$\begin{array}{l}\text { Model } \\
p\end{array}$} & \multirow[t]{2}{*}{$\begin{array}{c}\text { Corrected } \\
r^{2}\end{array}$} \\
\hline & B & $p$ & B & $p$ & B & $p$ & B & $p$ & B & $p$ & B & $p$ & B & $p$ & & \\
\hline Weight (Kg) & 0.899 & 0.146 & 0.806 & 0.206 & 0.252 & 0.681 & 1.274 & 0.034 & 0.085 & 0.889 & -0.519 & 0.399 & 1.140 & 0.059 & 0.024 & 0.122 \\
\hline $\mathrm{MI}\left(\mathrm{kg} / \mathrm{m}^{2}\right)$ & 0.275 & 0.215 & 0.218 & 0.342 & 0.032 & 0.884 & 0.480 & 0.026 & -0.025 & 0.910 & -0.194 & 0.378 & 0.430 & 0.047 & 0.132 & 0.060 \\
\hline $\begin{array}{l}\text { Waist } \\
\text { circumference } \\
\text { (cm) }\end{array}$ & 0.731 & 0.446 & 1.392 & 0.157 & -0.107 & 0.910 & 1.618 & 0.083 & 0.064 & 0.946 & -0.722 & 0.447 & 0.624 & 0.508 & 0.559 & -0.014 \\
\hline \multicolumn{17}{|l|}{ Bioimpedance } \\
\hline at mass (kg) & 0.613 & 0.394 & -0.036 & 0.962 & 1.358 & 0.053 & 1.185 & 0.091 & -0.215 & 0.760 & -0.424 & 0.552 & 0.639 & 0.365 & 0.128 & 0.061 \\
\hline \multicolumn{17}{|l|}{ DXA } \\
\hline at mass $(\mathrm{kg})$ & 0.949 & 0.063 & 0.819 & 0.120 & 0.434 & 0.392 & 1.211 & 0.015 & 0.050 & 0.921 & 0.154 & 0.763 & 0.806 & 0.109 & 0.133 & 0.059 \\
\hline $\begin{array}{l}\text { Total } \\
\text { Cholesterol } \\
(\mathrm{mg} / \mathrm{dl})\end{array}$ & 3.886 & 0.670 & 0.444 & 0.962 & -13.795 & 0.123 & 5.041 & 0.573 & -2.462 & 0.783 & -8.968 & 0.319 & -16.091 & 0.071 & 0.381 & 0.010 \\
\hline $\begin{array}{l}\text { HDL-c (mg/ } \\
\text { dl) }\end{array}$ & -0.786 & 0.612 & -2.045 & 0.199 & 2.055 & 0.178 & 0.558 & 0.714 & -0.951 & 0.531 & -1.558 & 0.308 & -0.247 & 0.872 & 0.311 & 0.021 \\
\hline DL-c (mg/dl) & 5.174 & 0.522 & 1.930 & 0.817 & -13.268 & 0.095 & -0.164 & 0.984 & -2.581 & 0.745 & -4.266 & 0.594 & -13.979 & 0.077 & 0.348 & 0.015 \\
\hline TG (mg/dl) & -2.511 & 0.865 & 2.792 & 0.855 & 7.639 & 0.601 & 23.238 & 0.107 & 5.349 & 0.712 & -15.720 & 0.281 & -9.324 & 0.522 & 0.471 & -0.003 \\
\hline $\begin{array}{l}\text { Glucose } \\
(\mathrm{mg} / \mathrm{dl})\end{array}$ & 3.560 & 0.648 & -8.493 & 0.290 & 6.908 & 0.370 & -5.614 & 0.464 & 2.408 & 0.753 & 7.928 & 0.303 & 9.467 & 0217 & 0.781 & -0.035 \\
\hline Insulin (IU/mg) & -1.662 & 0.233 & -1.144 & 0.427 & -1.814 & 0.188 & -0.664 & 0.629 & -2.546 & 0.061 & -2.572 & 0.060 & -1.597 & 0.246 & 0.198 & -0.063 \\
\hline HOMA & -0.539 & 0.299 & -0.487 & 0.364 & -0.151 & 0.770 & -0.371 & 0.468 & -0.666 & 0.190 & -0.465 & 0.365 & -0.382 & 0.457 & 0.894 & 0.044 \\
\hline ALT (U/L) & -6.226 & 0.049 & -6.852 & 0.035 & -4.413 & 0.160 & -5.795 & 0.062 & 3.721 & 0.232 & 3.708 & 0.238 & 5.855 & 0.060 & 0.066 & 0.089 \\
\hline AST (U/L) & -3.557 & 0.051 & -4.539 & 0.015 & 0.084 & 0.963 & -5.046 & 0.004 & 1.610 & 0.371 & 1.580 & 0.384 & 4.699 & 0.008 & 0.020 & 0.131 \\
\hline
\end{tabular}

n-3 FA, n-3 Fatty Acids; TAC, Total Antioxidant Capacity; Gl, Glycemic Index: GL, Glycemic Load; HEI, Healthy Eating Index; BMI, Body Mass Index; DXA, Dual-energy X-ray Absorptiometry; HDL-c, High Density Lipoprotein-cholesterol; LDL-c, Low Density Lipoprotein-cholesterol; TG, Triglycerides; HOMA, Homeostasis Model Assessment; ALT, Alanine minotransferase; AST, Aspartate aminotranferase. $p<0.05$ was set-up as statistically significant.

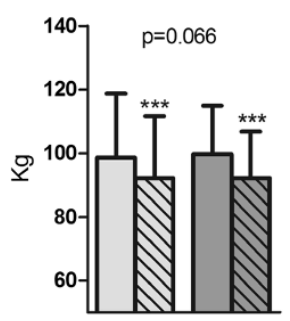

Weight

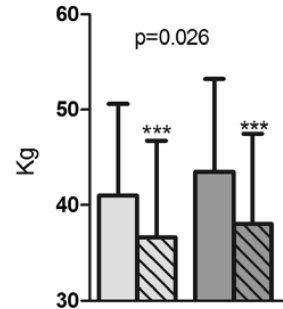

Fat mass

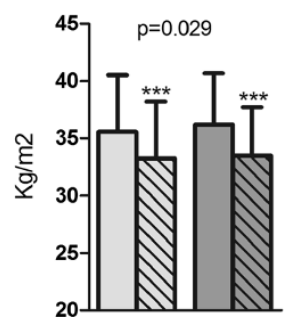

BMI

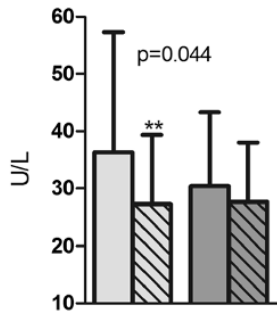

ALT

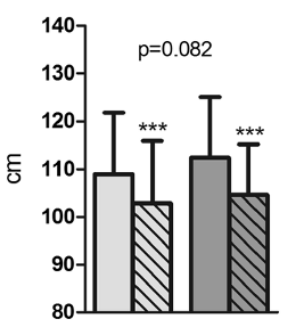

Waist circumference

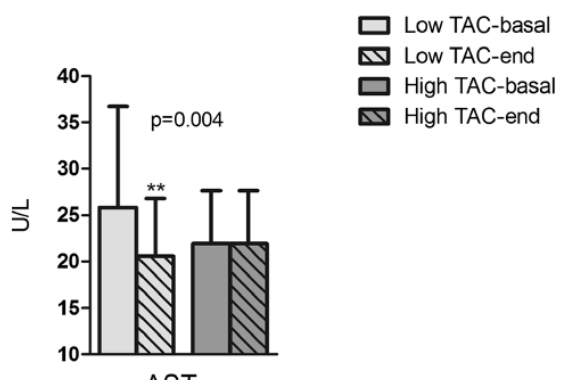

AST

Figure 2 Changes on selected parameters categorized by low $\left(<10.629 \mathrm{mmol} \mathrm{day}^{-1}, \mathrm{n}=45\right)$ or high $\left(>10.629 \mathrm{mmol}^{\text {day }}{ }^{-1}, \mathrm{n}=45\right)$ Total Antioxidant Capacity. BMI: Body Mass Index; ALT: Alanine aminotransferase; AST: Aspartate aminotranferase. p-values comparing the differences between low-TAC and high-TAC groups. 
Table 5 Analysis assessing diet and sex interactions concerning anthropometric and biochemical markers

\begin{tabular}{|c|c|c|c|c|c|c|c|}
\hline \multirow[t]{2}{*}{ Variable } & \multicolumn{4}{|c|}{ Groups } & \multicolumn{3}{|c|}{ ANOVA $2 \times 2$} \\
\hline & $\begin{array}{c}\text { Control-men } \\
(n=27)\end{array}$ & $\begin{array}{l}\text { Control-women } \\
(n=21)\end{array}$ & RESMENA-men $(n=24)$ & RESMENA-women $(n=24)$ & DIET & SEX & Diet* sex \\
\hline$\Delta$ Weight (Kg) & $-7.60 \pm 3.29$ & $-5.61 \pm 2.49$ & $-7.73 \pm 2.58$ & $-6.45 \pm 3.09$ & 0.416 & 0.007 & 0.550 \\
\hline$\Delta \mathrm{BMI}\left(\mathrm{kg} / \mathrm{m}^{2}\right)$ & $-2.56 \pm 1.12$ & $-2.29 \pm 1.03$ & $-2.55 \pm 0.90$ & $-2.49 \pm 1.10$ & 0.677 & 0.452 & 0.620 \\
\hline$\Delta$ Waist circumference $(\mathrm{cm})$ & $-6.57 \pm 4.02$ & $-7.01 \pm 5.87$ & $-8.15 \pm 2.88$ & $-6.80 \pm 4.65$ & 0.454 & 0.620 & 0.324 \\
\hline$\Delta$ Bioimpedance Fat mass $(\mathrm{kg})$ & $-6.08 \pm 4.92$ & $-4.28 \pm 1.84$ & $-5.90 \pm 2.64$ & $-4.89 \pm 3.50$ & 0.764 & 0.054 & 0.582 \\
\hline$\Delta$ DXA Fat mass $(\mathrm{kg})$ & $-5.13 \pm 2.80$ & $-3.99 \pm 1.49$ & $-5.71 \pm 1.95$ & $-4.78 \pm 2.75$ & 0.156 & 0.034 & 0.835 \\
\hline$\Delta$ Total Cholesterol (mg/dl) & $-15.31 \pm 35.58$ & $-19.05 \pm 30.86$ & $-22.25 \pm 44.19$ & $-10.42 \pm 49.55$ & 0.921 & 0.635 & 0.362 \\
\hline$\Delta \mathrm{HDL}-\mathrm{c}(\mathrm{mg} / \mathrm{dl})$ & $-2.01 \pm 7.10$ & $-6.67 \pm 6.98$ & $-0.61 \pm 7.29$ & $-3.32 \pm 6.03$ & 0.098 & 0.011 & 0.495 \\
\hline$\Delta \mathrm{LDL}-\mathrm{c}(\mathrm{mg} / \mathrm{dl})$ & $-6.12 \pm 25.04$ & $-7.48 \pm 27.41$ & $-10.82 \pm 40.17$ & $-0.51 \pm 47.30$ & 0.880 & 0.553 & 0.440 \\
\hline$\Delta \mathrm{TG}(\mathrm{mg} / \mathrm{dl})$ & $-35.88 \pm 78.11$ & $-24.50 \pm 61.90$ & $-54.08 \pm 88.48$ & $-32.96 \pm 69.79$ & 0.399 & 0.304 & 0.757 \\
\hline$\Delta$ Glucose $(\mathrm{mg} / \mathrm{dl})$ & $-18.53 \pm 36.01$ & $-5.91 \pm 19.86$ & $-7.33 \pm 26.55$ & $-19.84 \pm 46.17$ & 0.847 & 0.994 & 0.079 \\
\hline$\Delta$ Insulin (IU/mg) & $-7.68 \pm 9.02$ & $-3.37 \pm 3.58$ & $-6.26 \pm 5.02$ & $-4.16 \pm 5.25$ & 0.690 & 0.022 & 0.486 \\
\hline$\triangle \mathrm{HOMA}$ & $-2.64 \pm 2.65$ & $-1.35 \pm 1.68$ & $-1.74 \pm 1.63$ & $-2.02 \pm 2.83$ & 0.818 & 0.293 & 0.099 \\
\hline$\Delta \mathrm{ALT}(\mathrm{U} / \mathrm{L})$ & $-13.68 \pm 19.36$ & $-6.52 \pm 12.77$ & $-3.33 \pm 10.70$ & $3.64 \pm 15.38$ & 0.001 & 0.026 & 0.975 \\
\hline$\Delta \mathrm{AST}(\mathrm{U} / \mathrm{L})$ & $-6.49 \pm 11.74$ & $-3.37 \pm 6.16$ & $-0.28 \pm 6.13$ & $0.88 \pm 6.51$ & 0.003 & 0.210 & 0.562 \\
\hline
\end{tabular}

BMI, Body Mass Index; DXA, Dual-energy X-ray Absorptiometry; HDL-c, High Density Lipoprotein-cholesterol; LDL-c, Low Density Lipoprotein-cholesterol; TG, Triglycerides; HOMA, Homeostasis Model Assessment; ALT, Alanine aminotransferase; AST, Aspartate aminotranferase. $p<0.05$ was set-up as statistically significant.

profile did not apparently induce changes on any anthropometrical parameters between the experimental groups. Different studies have shown high-protein intake effects in relation with body weight changes, specifically on weight regain. However, those effects were found in the long-term [10] while the present work focused on the effects of an 8-week dietary treatment.

Interestingly, our study showed an inverse association between protein intake and both ALT and AST transaminases levels. These enzymes are unspecific markers of hepatic
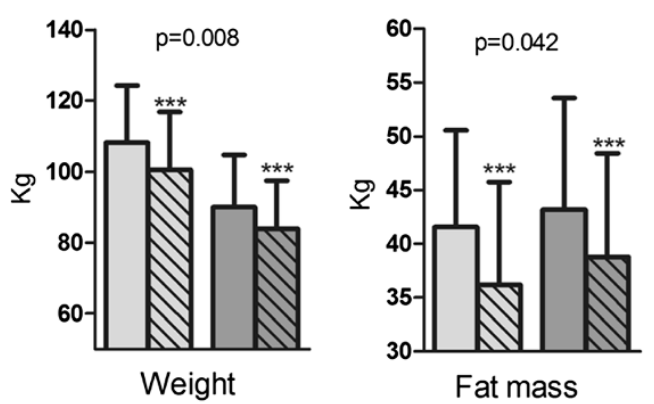

Fat mass

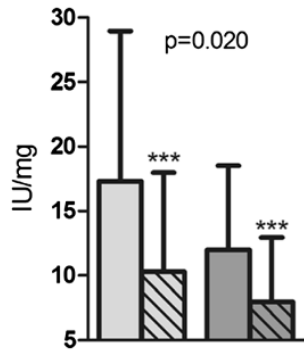

Insulin

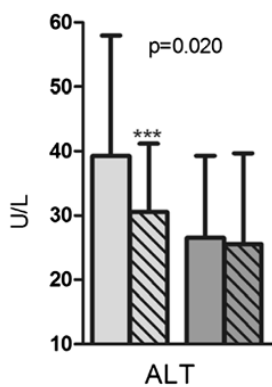

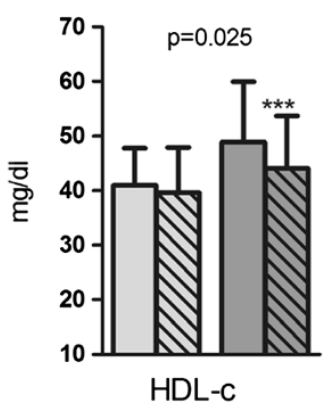

Figure 3 Changes on anthropometric and biochemical selected parameters regarding gender, male $(n=51)$ or female $(n=45)$. HDL-c: High Density Lipoprotein-cholesterol; ALT: Alanine aminotransferase. $p$-values comparing the differences between male and female groups. 
function [28]. Low-serum transaminases levels are found under normal conditions, indicating proper function of the liver, while increased serum values are related to hepatic dysfunction [28]. They have shown a correlation with insulin resistance and later development of diabetes, liver lipid content and features of non-alcoholic fatty liver disease. The experimental data are consistent with those other studies and suggest that moderately-high protein diets could influence negatively liver function. Concerning transaminases modification, it is important to notice that some differences were found before starting the intervention. For that reason we performed a percentage of change analyses in addition to the absolute values approach, in order to attenuate the possible bias. However, similar outcomes were obtained when applying this analysis, therefore, absolute values were maintained in Table 3.

Regarding the increased meal frequency, no differences in body weight loss in the context of iso-energetic energyrestricted diets were found, as also was reported by Cameron et al. 2009 [7]. Nevertheless, a direct relationship between increased meal frequency and the loss of fat mass was observed. With respect to biochemical parameters, no influences were found. However, Heden et al. 2012 observed that meal frequency differentially altered triglycerides and insulin postprandial concentrations [29].

The beneficial properties of $n-3$ fatty acids have been widely studied $[9,16]$. In our study, a positive relationship between n-3 fatty acids intake and the reduction of fat mass was detected, being consistent with previous human studies [16].

GI and GL are two concepts that refer to the absorption rate of carbohydrates [26]. Increased values have been reported as potential type- 2 Diabetes Mellitus risk factors [5]. In this sense, an encouraging result was obtained in our study, since we found a trend towards a reduction in insulin levels related to lower values of GI and GL in diet, in agreement with Bao et al. 2010 [30].

In order to assess the quality of the diet, numerous authors have designed and developed indexes or scores such as the Healthy Eating Index, the Alternate Healthy Eating Index or the Diet Quality Index and derivatives [14]. Most of them, take into consideration the Mediterranean Diet guidelines, widely recognized as a healthy pattern [30]. They consist on a single score that results from computing different component such as foods, food groups or a combination of foods and nutrients. In this context the HEI score was selected, obtained from the DIAL software. It takes into account macro and micronutrients intake, as well as food variety, to design the RESMENA diet. Considering the HEI score, a trend towards influencing weight loss and total cholesterol, LDL-c, ALT and AST levels was found. Other works evaluating Mediterranean-based patterns reported similar results regarding lipid metabolism and hepatic function markers [31,32].
The most relevant finding of this study is in relation to dietary TAC. This parameter has been recently considered as a useful tool to assess the effects of dietary antioxidants, since it has been positively associated with plasma total antioxidant capacity [33]. After 8 weeks of intervention, we evidenced positive associations between the dietary TAC and the reduction of weight, BMI, waist circumference and fat mass. Regarding these anthropometric measurements, our findings are in accordance with previous studies that also reported benefits of dietary TAC and antioxidants compounds on adiposity and obesity indicators [31,34]. This link may be associated with a reduction of cardiovascular risk, as previously described in other populations [35]. We also found an effect on ALT and AST transaminases suggesting an impact of the dietary TAC on hepatic metabolism. These data suggest that dietary TAC, as a measure of antioxidant intake, must be useful to assess the role of antioxidant intake as a single factor in the field of antioxidant consumption and disease prevention or therapy.

Contrary to most of the evaluated parameters, HDL-c values did not improve with none of the dietary treatments, which can be explained by the fact that the reduction on total cholesterol entails a reduction of this cholesterol fraction too, as previously reported by other researchers [36]. However, some other authors found higher HDL-c serum levels after similar dietary interventions [37] especially when containing fish or fish derived products [16,38]. Despite our dietary strategy also focused on n-3 fatty acids intake, the participants did not reach a perfect adherence to this point, so that this can also contribute to the fact that HDL-c was found to decrease after the dietary intervention. Other important factor in relation to HDL-c is physical activity. In this sense, the participants were asked to maintain the normal activity and no exercise advice was given, which may allow discard differences due to physical activity changes.

Differences between males and females regarding anthropometric and biochemical parameters have been widely investigated $[1,7,39]$. In this sense, we analyzed gender influence on the studied variable changes. Body weight loss was higher in men than women, due to the also higher restriction regarding absolute amount of calories. This greater reduction of weight was accompanied by an also higher decrease of fat mass, as previously reported [7]. Regarding biochemical parameters, insulin as well as ALT blood levels were significantly decreased within this group in accordance with previous studies [1]. On the contrary, HDL-c reduction was greater among the women group, as other studies reported [40], which confirms the influence of sex on this cholesterol fraction. Taken together, these outcomes indicate that gender may be taken into account in order to design specific dietary plans for males and females. 
This work could benefit of increasing sample size. Additionally, although the adherence to the diet was acceptable, this kind of treatments could show higher benefits when reaching a stricter follow-up of the dietary pattern. On the other hand, we have analyzed the effects of this treatment on obese adults with MetS features. The effectiveness of this pattern should be also evaluated in a younger population since obesity and MetS rates have increased alarmingly among childhood [41] and they represent a development problem [42] leading to an increased morbimortality at the adult age [43].

\section{Conclusion}

Taken together, the results of this study indicate that RESMENA diet could be considered as a new dietary strategy in order to improve anthropometrical and biochemical parameters in obese subjects presenting MetS manifestations. Furthermore, dietary TAC seems to be, among all the analyzed dietary aspects, the most relevant one in the obesity related markers.

\section{Abbreviations \\ AHA: American Heart Association; ALT: Alanine aminotransferase; AST: Aspartate aminotransferase; BMI: Body mass index; DXA: Dual-energy X- ray Absorptiometry; Gl: Glycemic index; GL: Glycemic load; HDL-c: High Density Lipoprotein-cholesterol; HEl: Healthy Eating Index; LDL-c: Low Density Lipoprotein-cholesterol; MetS: Metabolic syndrome; PQ: Protein Quality; PUFA: Poly Unsaturated Fatty Acids; TAC: Total antioxidant capacity; WHO: World Health Organisation.}

\section{Competing interests}

The authors declare that they have no competing interests.

\section{Authors' contributions}

The authors contributions were as follows: PLL contributed to the design and the fieldwork, data collection, analysis and writing of the manuscript. RI and IA were involved in the design and the fieldwork. IBP contributed to the sample collection, interpretation and critical reading of the last version. SNC and LF were involved in recruitment and volunteers selection as well as in critical reading of the manuscript. MAZ was responsible for the general coordination, follow-up, design and financial management. JAM, project coleader, was responsible of the follow-up, design, financial management and editing of the manuscript. All the authors actively participated in the manuscript preparation, as well as read and approved the final manuscript.

\section{Acknowledgements \\ This work was supported by the Health Department of the Government of Navarra (48/2009), the Linea Especial about Nutrition, Obesity and Health (University of Navarra LE/97) and CIBERobn and RETICS. Government of Navarra provided a pre-doctoral research grant to Patricia Lopez-Legarrea (Pre-doctoral no 233/2009). We acknowledge the volunteers for their participation in the study and the physician Blanca E. Martinez de Morentin, the nurse Salome Perez and the technician Veronica Ciaurriz for the excellent technical assistance.}

\section{Author details}

${ }^{1}$ Department of Nutrition, Food Science and Physiology, University of Navarra, Irunlarrea rd 1, Pamplona 31008, Spain. ${ }^{2}$ Biodonostia Health Research Institute, Doctor Begiristain rd (no number), San Sebastian 20014, Spain. ${ }^{3}$ Hospital Complex of Navarra, Irunlarrea rd 3, Pamplona 31008, Spain. ${ }^{4}$ CIBERobn. Carlos III Health Research Institute, Madrid, Spain.

Received: 20 November 2012 Accepted: 22 January 2013 Published: 13 February 2013

\section{References}

1. Ejike CE, ljeh II: Obesity in young-adult nigerians: variations in prevalence determined by anthropometry and bioelectrical impedance analysis, and the development of \% body fat prediction equations. Int Arch Med 2012, 5(1):22.

2. Hermsdorff HH, Zulet MA, Abete I, Martinez JA: Discriminated benefits of a Mediterranean dietary pattern within a hypocaloric diet program on plasma RBP4 concentrations and other inflammatory markers in obese subjects. Endocrine 2009, 36(3):445-451.

3. Eckel RH, Grundy SM, Zimmet PZ: The metabolic syndrome. Lancet 2005, 365(9468):1415-1428.

4. Marchetti E, Monaco A, Procaccini L, Mummolo S, Gatto R, Tete S, Baldini A, Tecco S, Marzo G: Periodontal disease: the influence of metabolic syndrome. Nutr Metab (Lond) 2012, 9(1):88.

5. Aller EE, Abete I, Astrup A, Martinez JA, Van Baak MA: Starches, sugars and obesity. Nutrients. 2011, 3(3):341-369.

6. Larsen TM, Dalskov SM, Van Baak M, Jebb SA, Papadaki A, Pfeiffer AF, Martinez JA, Handjieva-Darlenska T, Kunesova M, Pihlsgard M, Stender S, Holst C, Saris WH, Astrup A: Diets with high or low protein content and glycemic index for weight-loss maintenance. N Engl J Med 2010, 363(22):2102-2113.

7. Cameron JD, Cyr MJ, Doucet E: Increased meal frequency does not promote greater weight loss in subjects who were prescribed an 8-week equi-energetic energy-restricted diet. Br J Nutr 2009, 103(8):1098-1101.

8. Grube B, Chong PW, Lau KZ, Orzechowski HD: A Natural Fiber Complex Reduces Body Weight in the Overweight and Obese: A Double-Blind, Randomized, Placebo-Controlled Study. Obesity (Silver Spring); 2012.

9. Peairs AD, Rankin JW, Lee YW: Effects of acute ingestion of different fats on oxidative stress and inflammation in overweight and obese adults. Nutr J 2011, 10:122.

10. Gogebakan O, Kohl A, Osterhoff MA, Van Baak MA, Jebb SA, Papadaki A, Martinez JA, Handjieva-Darlenska T, Hlavaty P, Weickert MO, Holst C, Saris WH, Astrup A, Pfeiffer AF: Effects of weight loss and long-term weight maintenance with diets varying in protein and glycemic index on cardiovascular risk factors: the diet, obesity, and genes (DiOGenes) study: a randomized, controlled trial. Circulation 2011, 124(25):2829-2838.

11. Abete I, Goyenechea E, Zulet MA, Martinez JA: Obesity and metabolic syndrome: potential benefit from specific nutritional components. Nutr Metab Cardiovasc Dis 2010, 21 (Suppl 2):B1-B15.

12. Pellegrini N, Serafini M, Salvatore S, Del Rio D, Bianchi M, Brighenti F: Total antioxidant capacity of spices, dried fruits, nuts, pulses, cereals and sweets consumed in Italy assessed by three different in vitro assays. Mol Nutr Food Res 2006, 50(11):1030-1038.

13. Ghiselli A, Serafini M, Natella F, Scaccini C: Total antioxidant capacity as a tool to assess redox status: critical view and experimental data. Free Radic Biol Med 2000, 29(11):1106-1114.

14. Puchau B, Zulet MA, De Echavarri AG, Hermsdorff HH, Martinez JA: Dietary total antioxidant capacity: a novel indicator of diet quality in healthy young adults. J Am Coll Nutr 2009, 28(6):648-656.

15. Abete I, Parra D, Martinez JA: Legume-, fish-, or high-protein-based hypocaloric diets: effects on weight loss and mitochondrial oxidation in obese men. J Med Food 2009, 12(1):100-108.

16. Ramel A, Martinez JA, Kiely M, Bandarra NM, Thorsdottir I: Effects of weight loss and seafood consumption on inflammation parameters in young, overweight and obese European men and women during 8 weeks of energy restriction. Eur J Clin Nutr 2010, 64(9):987-993.

17. Goto M, Morita A, Goto A, Sasaki S, Aiba N, Shimbo T, Terauchi Y, Miyachi M, Noda M, Watanabe S: Dietary glycemic index and glycemic load in relation to $\mathrm{HbA} 1 \mathrm{c}$ in Japanese obese adults: a cross-sectional analysis of the Saku control obesity program. Nutr Metab (Lond) 2012, 9(1):79.

18. Del Rio D, Agnoli C, Pellegrini N, Krogh V, Brighenti F, Mazzeo T, Masala G, Bendinelli B, Berrino F, Sieri S, Tumino R, Rollo PC, Gallo V, Sacerdote C, Mattiello A, Chiodini P, Panico S: Total antioxidant capacity of the diet is associated with lower risk of ischemic stroke in a large Italian cohort. J Nutr 2011, 141(1):118-123.

19. Zulet MA, Bondia-Pons I, Abete I, de la Iglesia R, Lopez-Legarrea P, Forga L, Navas-Carretero S, Martinez JA: The reduction of the metabolyc syndrome in Navarra-Spain (RESMENA-S) study: a multidisciplinary strategy based on chrononutrition and nutritional education, together with dietetic and psychological control. Nutr Hosp 2011, 26(1):16-26. 
20. Krauss RM, Eckel RH, Howard B, Appel LJ, Daniels SR, Deckelbaum RJ Erdman JW Jr, Kris-Etherton P, Goldberg IJ, Kotchen TA, Lichtenstein AH, Mitch WE, Mullis R, Robinson K, Wylie-Rosett J, St Jeor S, Suttie J, Tribble DL, Bazzarre TL: AHA Dietary Guidelines: revision 2000: A statement for healthcare professionals from the Nutrition Committee of the American Heart Association. Stroke 2000, 31(11):2751-2766.

21. Alberti KG, Zimmet $P$, Shaw J: The metabolic syndrome--a new worldwide definition. Lancet 2005, 366(9491):1059-1062.

22. Food and Nutrition Board, National Research Council: Recomended Dietary Allowances. 10th edition. Washington, DC: The National Academy Press; 1989.

23. Basiotis PP, Carlson A, Gerrior SA, Juan WY, Lino M: The Healthy Eating Index: 1999-2000 (CNPP-12): US Department of Agriculture, Center for Nutrition Policy and Promotion; 2002.

24. Loenneke JP, Wilson JM, Manninen AH, Wray ME, Barnes JT, Pujol TJ: Quality protein intake is inversely related with abdominal fat. Nutr Metab (Lond) 2012, 9(1):5.

25. Carlsen MH, Halvorsen BL, Holte K, Bohn SK, Dragland S, Sampson L, Willey C, Senoo H, Umezono Y, Sanada C, Barikmo I, Berhe N, Willett WC, Phillips KM, Jacobs DR Jr, Blomhoff R: The total antioxidant content of more than 3100 foods, beverages, spices, herbs and supplements used worldwide. Nutr J 2010, 9:3

26. Foster-Powell K, Holt SH, Brand-Miller JC: International table of glycemic index and glycemic load values: 2002. Am J Clin Nutr 2002, 76(1):5-56.

27. Abete I, Astrup A, Martinez JA, Thorsdottir I, Zulet MA: Obesity and the metabolic syndrome: role of different dietary macronutrient distribution patterns and specific nutritional components on weight loss and maintenance. Nutr Rev 2010, 68(4):214-231.

28. Yang HR, Kim HR, Kim MJ, Ko JS, Seo JK: Noninvasive parameters and hepatic fibrosis scores in children with nonalcoholic fatty liver disease. World J Gastroenterol 2012, 18(13):1525-1530.

29. Heden TD, Liu Y, Sims L, Whaley-Connell AT, Chockalingam A, Dellsperger KC, Kanaley JA: Meal frequency differentially alters postprandial triacylglycerol and insulin concentrations in obese women. Obesity (Silver Spring) 2012,

30. Salas-Salvado J, Martinez-Gonzalez MA, Bullo M, Ros E: The role of diet in the prevention of type 2 diabetes. Nutr Metab Cardiovasc Dis 2011, 21(Suppl 2):B32-B48.

31. Psaltopoulou T, Panagiotakos DB, Pitsavos C, Chrysochoou C, Detopoulou P, Skoumas J, Stefanadis C: Dietary antioxidant capacity is inversely associated with diabetes biomarkers: The ATTICA study. Nutr Metab Cardiovasc Dis 2009, 21:561-7.

32. Pitsavos C, Panagiotakos DB, Tzima N, Chrysohoou C, Economou M, Zampelas A, Stefanadis C: Adherence to the Mediterranean diet is associated with total antioxidant capacity in healthy adults: the ATTICA study. Am J Clin Nutr 2005, 82(3):694-699.

33. Bahadoran Z, Golzarand M, Mirmiran P, Shiva N, Azizi F: Dietary total antioxidant capacity and the occurrence of metabolic syndrome and its components after a 3-year follow-up in adults: Tehran Lipid and Glucose Study. Nutr Metab (Lond) 2012, 9(1):70.

34. Zulet MA, Puchau B, Hermsdorff HH, Navarro C, Martinez JA: Vitamin A intake is inversely related with adiposity in healthy young adults. J Nutr Sci Vitaminol (Tokyo) 2008, 54(5):347-352.

35. Puchau B, Zulet MA, De Echavarri AG, Hermsdorff HH, Martinez JA: Dietary total antioxidant capacity is negatively associated with some metabolic syndrome features in healthy young adults. Nutrition 2010, 26(5):534-541.

36. Aicher BO, Haser EK, Freeman LA, Carnie AV, Stonik JA, Wang X, Remaley AT, Kato GJ, Cannon RO 3rd: Diet-induced weight loss in overweight or obese women and changes in high-density lipoprotein levels and function. Obesity (Silver Spring) 2012, 20(10):2057-2062.

37. Belalcazar LM, Lang W, Haffner SM, Hoogeveen RC, Pi-Sunyer FX, Schwenke DC, Balasubramanyam A, Tracy RP, Kriska AP, Ballantyne CM: Adiponectin and the mediation of HDL-cholesterol change with improved lifestyle: the Look AHEAD Study. J Lipid Res 2012, 53(12):2726-2733.

38. Smith KM, Barraj LM, Kantor M, Sahyoun NR: Relationship between fish intake, n-3 fatty acids, mercury and risk markers of CHD (National Health and Nutrition Examination Survey 1999-2002). Public Health Nutr 2009, 12(8):1261-1269

39. Campbell DD, Meckling KA: Effect of the protein:carbohydrate ratio in hypoenergetic diets on metabolic syndrome risk factors in exercising overweight and obese women. Br J Nutr 2012, 16:1-14.
40. Okuda N, Ueshima H, Okayama A, Saitoh S, Nakagawa H, Rodriguez BL, Sakata K, Choudhury SR, Curb JD, Stamler J: Relation of long chain n-3 polyunsaturated fatty acid intake to serum high density lipoprotein cholesterol among Japanese men in Japan and Japanese-American men in Hawaii: the INTERLIPID study. Atherosclerosis 2005, 178(2):371-379.

41. Haidar YM, Cosman BC: Obesity epidemiology. Clin Colon Rectal Surg 2011, 24(4):205-210

42. Giuca MR, Pasini M, Tecco S, Marchetti E, Giannotti L, Marzo G: Skeleta maturation in obese patients. Am J Orthod Dentofacial Orthop 2012, 142(6):774-779.

43. Park MH, Falconer C, Viner RM, Kinra S: The impact of childhood obesity on morbidity and mortality in adulthood: a systematic review. Obes Rev 2012, 13(11):985-1000.

doi:10.1186/1743-7075-10-22

Cite this article as: Lopez-Legarrea et al: Short-term role of the dietary total antioxidant capacity in two hypocaloric regimes on obese with metabolic syndrome symptoms: the RESMENA randomized controlled trial. Nutrition \& Metabolism 2013 10:22.

\section{Submit your next manuscript to BioMed Central and take full advantage of:}

- Convenient online submission

- Thorough peer review

- No space constraints or color figure charges

- Immediate publication on acceptance

- Inclusion in PubMed, CAS, Scopus and Google Scholar

- Research which is freely available for redistribution

Submit your manuscript at www.biomedcentral.com/submit
C) Biomed Central 